\title{
Apresentação
}

\section{As Transformações do Trabalho num Mundo Globalizado}

SÔNIA MARTA GUIMARÃES LARANGEIRA Professora titular do Departamento de Sociologia da UFRGS e Coordenadora do Programa de Pós-graduação em Sociologia do IFCH da UFRGS

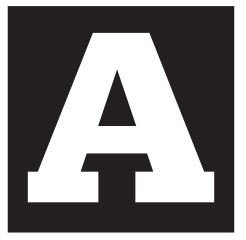

s últimas décadas têm sido pródigas em referências e análises que tentam descrever e explicar as dramáticas transformações que vêm ocorrendo na realidade do trabalho. As explicações sobre essa realidade e a avaliação de suas implicações sociais, como seria de esperar, não alcançaram consensos, ao contrário, resultaram em conclusões pautadas por divergências, polêmicas e controvérsias, em que perspectivas otimistas confrontam-se com perspectivas pessimistas. Tais posições, isoladamente, mostram-se, hoje, infundadas. Na verdade, as descontinuidades históricas colocam-nos diante de alternativas, que devem ser exploradas em suas potencialidades.

É verdade que a realidade se nos apresenta preocupante: altas taxas de desemprego, presença do desemprego estrutural, intensificação do ritmo de trabalho, crescimento do trabalho temporário e de tempo parcial, polarização em termos de qualificação e para os que permanecem no emprego a chamada "síndrome dos sobreviventes", angústia e medo, sentimentos que acompanham os não demitidos.

Entretanto, as novas tecnologias podem ser exploradas em suas dimensões positivas como na eliminação das funções rotineiras, repetitivas e degradantes, fonte de doenças e de insatisfação, tanto na esfera do traba- 
Iho fabril quanto na esfera dos serviços; ou como na realização de um trabalho polivalente, multifuncional, favorecendo a utilização do pensamento abstrato, permitindo uma maior interação do trabalhador com a máquina, já que o trabalho informático supõe essa interação. Sobretudo, haveria a possibilidade de reduzir ainda mais o tempo de trabalho necessário ao ganho para sobrevivência.

No decorrer desse processo de mudanças guiado pelas inovações tecnológicas e pela chamada globalização, parece ter se consolidado a crença de que tais fenômenos vieram para ficar, que seus efeitos são cumulativos e tendem a configurar uma nova dinâmica social, ainda que ajustes venham a ser feitos e que algumas realidades, hoje observadas, possam ser modificadas. A digitalização, por exemplo, representa uma mudança de paradigma, já que através dessa tecnologia estrutura-se uma nova lógica de ação sobre o mundo. É certo que esse quadro define-se como tendência e corre-se o risco de superestimar o volume de transformações, esquecendo as forças que permanecem. Entretanto, essa ressalva não desqualificaria o argumento. Seria difícil, por exemplo, negar que a sociedade industrial foi uma característica central do mundo ocidental, no século XX, ainda que proporção significativa desse mundo não pudesse ser considerada propriamente industrial. Todavia, os valores que pautavam as condutas dos indivíduos tinham como referência o mundo industrializado. Da mesma forma, embora as altas taxas atuais de desemprego não representem o fim do trabalho, há que se admitir que a natureza do desemprego e as novas modalidades de trabalho redefinem aspectos centrais da vida social. As mudanças que presenciamos não podem, portanto, ser subestimadas ou tratadas sob um ponto de vista socialmente superado (Supiot, 1999). Nesta perspectiva, discute-se se estaríamos ingressando numa nova sociedade, como o faz o artigo de Supervielle e Quiñones no dossiê Trabalho.

Observa-se, também, o desenvolvimento de iniciativas concretas no sentido de ajustar as políticas sociais à nova realidade considerando situações como a permanência do desemprego estrutural, a flexibilidade do 
trabalho e, em conseqüência, a maior mobilidade e menor compromisso ou laços das empresas com seus empregados, bem como diferentes arranjos de inserção no mercado de trabalho. O argumento é de que a legislação trabalhista foi concebida no contexto de relações de emprego do tipo fordista de produção (ainda que este não tenha sido universal, constituía-se em referência sobre cujos benefícios pautavam-se as reivindicações trabalhistas) tendo como pressuposto o empregado (mais que o trabalhador) estável em uma determinada empresa, do sexo masculino e chefe de família. A dificuldade estaria, pois, em acomodar tal legislação a uma nova dinâmica que prima pela mobilidade, por formas de inserção não convencionais ou não previstas anteriormente (como o trabalho no terceiro setor, por exemplo). Essa discussão está contemplada no artigo de Hespanha e Matos, também, neste dossiê.

Os artigos reunidos no corpo deste número da Revista Sociologias abordam diferentes aspectos sobre as transformações da realidade do trabalho e suas implicações sociais, discutindo questões atuais que resultam do amadurecimento do debate após o longo processo de mudanças, ainda em andamento. Mesmo partindo do estudo de realidades particulares, as análises tendem a avançar formulando questões mais abrangentes, como por exemplo, ao indagar sobre a existência de um novo modelo societal.

O artigo de Supervielle e Quiñones, ao examinar a questão da flexibilidade no Uruguai, introduz a discussão sobre a existência de um novo modelo societal, baseado em novo sistema simbólico em que a centralidade do trabalho, como fator organizador da sociedade, estaria sendo substituída pela centralidade da empresa; o arquétipo do trabalhador fabril pelo do trabalhador de serviços; a dimensão coletiva pela dimensão individual. Nessa perspectiva, o eixo das relações de trabalho deixaria de ser o conflito entre capital e trabalho, sendo introduzida uma dimensão externa, representada pelo cliente e pela opinião pública.

O artigo de Leite dedica-se ao debate de questões teóricometodológicas no contexto da Sociologia do Trabalho. A autora argumenta 
sobre a necessidade de se examinar a nova realidade sob a perspectiva da complexidade, da visão sistêmica e multidisciplinar, abandonando as visões dualistas e polares. Para ilustrar as possibilidades criadas pela nova realidade, Leite descreve uma experiência de reconversão econômica e social da região paulista do $\mathrm{ABC}$, baseada em nova proposta de governabilidade, incluindo novos atores sociais podendo constituir-se em alternativa superior em termos de padrões de cidadania.

Os artigos de Hespanha e Matos e de Palomino e Díaz abordam aspectos relacionados às novas institucionalidades. Hespanha e Matos discutindo a experiência da Comunidade Européia, mais especificamente de Portugal, destacam as possibilidades e limites da nova abordagem sobre as políticas sociais, cuja proposta reside em substituir as políticas passivas de compensação monetária - políticas de subsidiação - por políticas de ativação/inserção, voltadas a amenizar a exclusão social e moral dos desempregados através de sua efetiva participação na vida da comunidade. Palomino e Díaz, examinado o caso argentino, mostram como as transformações que atingem a realidade do trabalho, alcançam, também, o âmbito jurídico, promovendo um rebaixamento do direito trabalhista tradicional, estruturado na dimensão coletiva. Dessa forma, o direito trabalhista tradicional seria substituído pelo direito mercantil ou civil, em que desaparece a figura do trabalhador. Os dois artigos, ainda que tratando do mesmo tema - novas institucionalidades - evidenciam distintas realidades - a européia e a latinoamericana - no que se refere à natureza, ao conteúdo e à abordagem em relação à proteção social.

Cardoso analisa em seu artigo, os impactos da reestruturação sobre as opções dos trabalhadores por ela afetados na indústria de material de transporte do estado de São Paulo, inovando metodologicamente, ao utilizar-se de recursos estatísticos próprios à análise da transição no mercado de trabalho ("regressão de Cox"), procedimento que contribui para um maior refinamento no tratamento dos dados e, em conseqüência, maior precisão dos resultados. 
Os artigos de Santana e de Carvalho e Neves abordam as transformações do trabalho sob a perspectiva do sindicalismo. Santana examina a forma pela qual as centrais sindicais brasileiras avaliam e enfrentam a situação adversa, buscando garantir a sobrevivência do sindicalismo. $\mathrm{O}$ autor destaca as diferenças quanto às posições e estratégias adotadas por cada uma das centrais, mostrando também algumas convergências, como a crença de que a qualificação profissional seria uma boa maneira de enfrentar o desemprego (caberia remeter à conclusão de Cardoso em seu artigo acima mencionado: no caso por ele estudado, a qualificação formal seria requisito importante na contratação, mas não se constituiria em fator que impedisse a demissão).

Carvalho e Neves analisam as negociações realizadas por três sindicatos - bancários, metalúrgicos e de trabalhadores de telecomunicações evidenciando o caráter mais pragmático e propositivo assumido pelos sindicatos, no sentido de uma intervenção negociada que, no entanto, não encontraria correspondência entre os empresários. A regulação do Estado visando garantir um maior equilíbrio nas negociações seria, segundo os autores, de fundamental importância para o aprimoramento das relações de trabalho no Brasil. Concluem afirmando que a autonomia e liberdade sindical no Brasil, não poderiam prescindir da organização dos trabalhadores no local de trabalho.

O artigo de Holzmann argumenta que, a despeito das amplas transformações ocorridas na realidade do trabalho, originadas pelas inovações tecnológicas e organizacionais, há elementos de permanência. Refere-se, a autora, especialmente ao fenômeno da segregação das mulheres trabalhadoras no mercado de trabalho, embora em alguns aspectos mulheres se encontrassem em posição vantajosa em relação aos homens, por exemplo, no que se refere à formalização do trabalho. (Novamente, caberia referir aos achados de Cardoso, no artigo deste número: segundo o autor, as muIheres levam mais tempo do que os homens para serem demitidas, entretanto, quando despedidas têm maiores dificuldades em inserir-se no mer- 
cado de trabalho formal).

Devo dizer que foi um privilégio coordenar a organização do dossiê deste número da Revista Sociologias sobre a temática do trabalho e suas transformações na atualidade, reunindo estudiosos brasileiros, portugueses, uruguaios e argentinos, de reconhecida expressão na Sociologia do Trabalho. Tenho certeza que os leitores da Revista irão beneficiar-se com o conjunto de artigos aqui apresentados, por tratarem-se de textos que trazem novas abordagens e diferentes dimensões do problema em discussão, aprofundando e atualizando o debate sobre as transformações do trabalho.

\section{Referência Bibliográfica}

SUPIOT, Alain. The transfomation of work and the future of labour law in Europe: a multidisplinary perspective. International Labour Review. Vol 138, no. 1, Genebra, 1999, pp. 31-46. 